\title{
A comparative study between manual vacuum aspiration and electrical suction in first trimester MTP
}

\author{
Bijoy Kumar Dutta, Sudip Samanta \\ Correspondence: Dr Bijoy Kumar Dutta, Associate Professor, Department of Obstetrics \\ and Gynaecology, Gauhati Medical College, Guwahati, Assam, India; Email - \\ duttabijoy7@gmail.com
}

Distributed under Creative Commons Attribution-Share Alike 4.0 International.

\begin{abstract}
Objective: The objective of this study was to observe the efficacy of manual vacuum aspiration (MVA) and electrical suction/vacuum aspiration (EVA) for pregnancy termination and to compare the two techniques. Methodology: A prospective study of 200 cases of medical termination of unwanted pregnancy in first trimester was done by applying MVA and EVA at Gauhati Medical College and Hospital. Results: In this study majority of patients belonged to age group 26 - 30 years, Hindu religion and middle class. Maximum women were educated up to high school. Most of the patients had period of gestation between 6 to 8 weeks (44\%) followed by up to 6 weeks (36\%) in both the groups. Average blood loss in MVA was $33.9 \mathrm{ml}$ and that of EVA $85.45 \mathrm{ml}$. Blood loss in both the groups increased with increasing gestational age. Average time taken was 11.77 and 16.55 minutes in MVA and EVA respectively. In terms of complication, no major complication was found except in 9\% of cases MVA failed and had to be converted to EVA for complete evacuation. At postoperative period, mild bleeding (grade II) was seen in $22 \%$ cases mostly in patients of EVA group. As far as success rate is concerned, EVA got $100 \%$ while MVA got $91 \%$. Conclusion: Both the techniques were found to be almost equally effective. Though blood loss is slightly lesser in MVA but success rate in term of complete evacuation is better in EVA.
\end{abstract}

Keywords: Abortions, MTP, EVA, MVA, gravid, intra-operative complication.

Induced abortion is a deliberate attempt to remove product of conception from uterus. It has been estimated that 46 million pregnancies ended into abortion each year, and nearly 21.6 million of those are found to be unsafe and among them 21.2 million took place in developing countries. In India 10-19 unsafe abortions takes place per 1000 women ${ }^{1}$. In India, unsafe illegal abortion remains a serious health problem despite liberal laws established since $1^{\text {st }}$ April, 1972 for medical termination of pregnancy ${ }^{2}$. In fact, unsafe abortion is one of the leading causes of maternal death in India.

Surgical methods of abortion have emerging as a safe alternative and effective back up for medical abortion in early pregnancy. Thus vacuum aspiration is used in > 97\% of cases for termination of pregnancy in the first trimester. In the year 2000, government introduced national policy which stated the need for adopting simple technologies such as MVA and EVA for elimination of onerous procedures. The objective of the present experiment was to study the safety of manual vacuum

Received: 20 th November 2017. Accepted: 15 th December 2017.

Dutta BK, Samanta S. A comparative study between manual vacuum aspiration and electrical suction in first trimester MTP. The New Indian Journal of OBGYN. 2018; 4(2): $154-57$. 
aspiration (MVA) and electrical suction/vacuum aspiration (EVA) for pregnancy termination and to compare the two techniques.

\section{Methodology}

The study was conducted on patients attending the outpatient Department of Obstetrics and Gynaecology of Gauhati Medical College and Hospital. Required approval of institutional ethical committee was obtained and the study was conducted for duration of 1 year. A total of 200 pregnant women were included in the study after obtaining informed consent from them. MVA and EVA were performed on 100 women each.

\section{Inclusion criteria}

- Age $>15$ years

$\circ$ Gestational age $\leq 12$ weeks by Last Menstrual Period (LMP)

\section{Exclusion criteria}

- Presence of uterine fibroids, polyp, pelvic infection, bleeding disorders or any structural anomaly

- Suspected ectopic pregnancy or molar pregnancy

- Taken any abortificient drugs.

Pregnant women in the first trimester attending OPD were enrolled in the study. A detailed history was taken in a questionnaire including age, religion, residency status, marital status, socioeconomic status, educational status and living issue number. Chief complain, past obstetrical and menstrual history, any contraceptive method taken previously, any past medical or surgical history etc were noted. ABO grouping and RH typing, haemoglobin estimation, urine examination for albumin and sugar was done.

\section{Method of abortion}

Cases were selected randomly and subjected to vacuum aspiration by either MVA or EVA. Local anaesthesia or sedation was used as per suitability to the patient. Instruments used for MVA were manual vacuum aspirator, Sim's posterior vaginal speculum, anterior vaginal wall retractor, vulsellum, rubber catheter and Karman's cannula. Per vaginal examination done after emptying the bladder. Sim's posterior vaginal speculum was introduced to hold the cervix. Cannula was inserted through the cervix and size of uterus noted. Dilation of cervix was done with gradually larger sized cannula. Then cannula of appropriate size was inserted into the uterine cavity and cavity contents were evacuated. After that contents of the syringe were kept in a clear receptacle of clean water for examination.

For EVA, suction apparatus and jar were connected to electric source. The cervix was dilated with metal dilators. Suction cannula fitted to the suction apparatus was then introduced into the uterus, taking care to place the tip of the cannula in the middle of the uterine cavity. The pressure of the suction apparatus was raised to 400-600 $\mathrm{mm}$ of $\mathrm{Hg}$. The cannula was moved up and down and rotated within the uterine cavity with pressure on cavity contents were evacuated.

Patients were counselled regarding the procedure, risk associated with the procedure, care after the procedure, contraceptive methods, risks of repeated abortions etc. Data were analyzed by using InStat 3 software.

\section{Results}

In this study, majority cases belonged to age group 2630 years (45.5\%) followed by $21-25$ years (29\%) in both the groups. Religion wise maximum (78\%) patients were Hindu. Most of the cases belonged to middle class group $(65 \%)$ and $52.5 \%$ patients were educated up to higher school. Significant number of cases (37\%) was third gravida followed by fourth gravida (33.5\%). Maximum

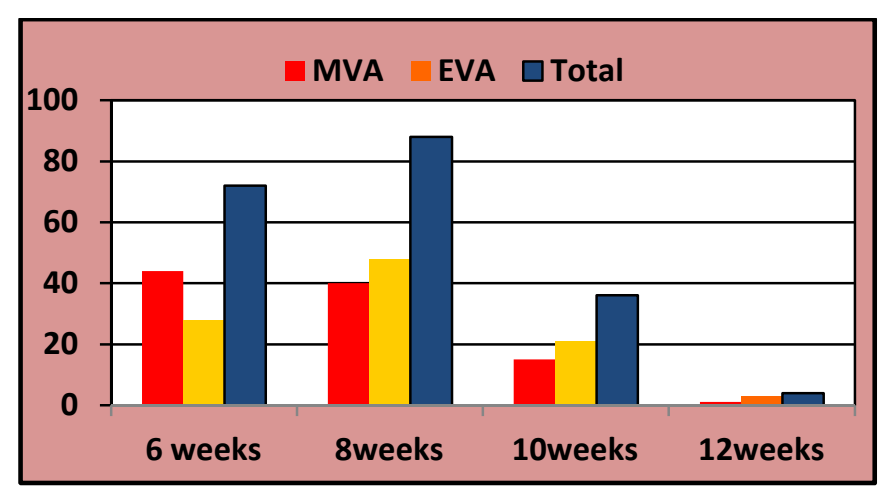

Figure 1: Distribution of cases according to size of uterus

patients had two living issues (47\%) followed by single living issues (38\%). Most of the patients had gestation period between 6 to 8 weeks (44\%) followed by up to 6 weeks $(36 \%)$ in both the groups. Figure 1 shows case distribution according to size of uterus in both the groups. Maximum cases had 8 weeks size uterus (44\%) followed by 6 weeks size uterus (36\%). Very few cases $(2 \%)$ had 
Table-1: Average blood loss in both the procedures

\begin{tabular}{ccccc}
\hline $\begin{array}{c}\text { Size of } \\
\text { uterus }\end{array}$ & $\begin{array}{c}\text { Blood loss }(\mathbf{m l}) \\
\text { MVA } \\
\text { mean } \pm \text { SD }\end{array}$ & $\begin{array}{c}\text { EVA } \\
\text { mean } \pm \text { SD }\end{array}$ & $\begin{array}{c}\text { t- } \\
\text { value }\end{array}$ & p-value \\
\hline 6 weeks & $13.97 \pm 7.36$ & $36.07 \pm 28.97$ & 4.836 & $<0.001$ Significant \\
8 weeks & $31.12 \pm 24.00$ & $83.02 \pm 37.00$ & 7.616 & $<0.001$ Significant \\
10 weeks & $88.66 \pm 29.96$ & $145.00 \pm 46.54$ & 3.960 & $<0.001$ Significant \\
12 weeks & $200.00 \pm 0.00$ & $167.00 \pm 57.73$ & - & - \\
Mean \pm SD & $33.9 \pm 35.00$ & $85.45 \pm 55.11$ & 7.454 & $<0.001$ Significant \\
\hline
\end{tabular}

comparable to study by Edward et al. ${ }^{3}$. Most of the patients were with 6-8 weeks gestational period while previous studies 4,5 recorded maximum patients with 8-10 weeks period.

Average blood loss was observed to be $51 \mathrm{ml}$ less in MVA than EVA which was similar to the study by other workers ${ }^{4,6}$. No intra-operative complications
12 weeks size uterus. Mean value of uterus size of the cases in MVA group was less than that of in EVA group. When average blood loss is considered (Table1), it has been found to increase with gestational age in both the study groups. Overall blood loss and gestational age wise

$\begin{aligned} & \text { Table 2: Comparison of intra operative complication in } \\
& \text { both the procedures }\end{aligned}$
\begin{tabular}{lcc}
\hline Complications & $\begin{array}{c}\text { MVA } \\
(\mathbf{n = 1 0 0})\end{array}$ & $\begin{array}{c}\text { EVA } \\
(\mathbf{n}=\mathbf{1 0 0})\end{array}$ \\
\hline Incomplete evacuation & 9 & 0 \\
Haemorrhage & 3 & 6 \\
Cervix laceration & - & - \\
Uterine perforation & - & - \\
Anaesthesia complication & - & - \\
\hline
\end{tabular}

blood loss is less (about $51 \mathrm{ml}$ ) in MVA in comparison to EVA and it is statistically significant. In post-operative period, most of the patients had Grade I bleeding (i.e. spotting or minimal bleeding) in both the groups.

Average time taken increases gradually with gestational period in both the groups. Mean time taken in

EVA is 5 min more than MVA. Mild pain was felt by $63 \%$ patients but severe pain was not observed. Incomplete evacuation was found in 9 cases of MVA leading to excessive bleeding. Ultimately, MVA procedure failed and it had to be converted to EVA for complete evacuation. In the procedure of EVA, no incomplete cases were found. Haemorrhage occurred more in EVA than MVA (Table 2).

\section{Discussion}

Unwanted pregnancy is a stress to society in India due to large number of women lacking proper education and not desiring contraceptive advices. Thus there is a need for safe, less costly and convenient procedure. In the present study, maximum patients in both the groups had uterus size 8 weeks followed by 6 weeks which is like uterine perforation, cervix laceration, anaesthesia complications occurred in the present case but in 9 cases of MVA had to be converted to EVA due to incompleteness and profuse bleeding. This is probably due to gestational age more than 10 weeks. This incompleteness is higher than other studies $5,7,8$. Incompleteness found at gestational age more than 10 weeks is mainly due to clogging of cannula, filling up of barrel with bulk of product of conceptus and blood before the procedure is over and thus requiring repeating of the procedure. Haemorrhage is higher in EVA than MVA in the present study and overall high in respect to other studies ${ }^{5,7,8}$ and mainly found when MTP was done at late gestational age of first trimester. Uterine perforation was nil in the present case, but Tasnim et al. ${ }^{9}$ got $2.4 \%$ cases in which uterine perforation occurred in MVA.

Success rate was calculated depending on numbers of the cases undergoing re-aspiration for incomplete abortion and retained products of conception. MVA showed $91 \%$ success rate as compared to $100 \%$ in EVA. It is mainly due to retained product in those cases where gestational age was more than 10 weeks and MVA tried. Till now various studies have been done with effectiveness ranging from $87-100 \%$ with majority exceeding $98 \%$ 4, 7, 10, 11 . MVA is as safe as EVA for abortions up to 10 weeks gestation and expanded use in an office setting might increase abortion access.

\section{Conclusion}

Manual vacuum aspiration and electrical suction both are effective and safe method for management of first trimester pregnancy. Though blood loss is slightly lesser in MVA but success rate in term of complete evacuation is better in EVA.

Conflict of interest: None. Disclaimer: Nil. 


\section{References}

1.Department of Reproductive Health and Research, World Health Organization. Unsafe abortion; global and regional estimates of the incidence of unsafe abortion and associated mortality. 6th edi. 2008.

2.Park K. Park's textbook of preventive and social medicine. 21st Edn. New Delhi: Banarasidas Bhanot; 2011. p.468.

3.Edwards S, Tureck R, Fredrick M, Huang X, Zhang J, Barnhart K. Patient Acceptability of Manual Vacuum Aspiration vs Electrical Vacuum Aspiration for early pregnancy loss. Journal of Women's health. 2007; 16: 143036.

4.Goswami S, Helen K, Dutta R. Manual vacuum aspiration and eletrical vacuum aspiration - A comparative study for first trimester MTP. The Journal of Obstetrics and Gynaecology of India. 2011; 53-6.

5.Agarwal S, Gupta D. Comparison of Manual Vacuum Aspiration vs Traditional Suction evacuation in First trimester MTP. Int J Res Med. 2013; 2(1):11- 4.

6.Kerure SB, Kerure RD, Sagarad SS, Biradar V. A comparative study of manual vaccum aspiration (MVA) \& electric vaccum aspiration (EVA) for pregnancy termination of upto 10 weeks gestation. Int J Reprod Contracept Obstet gynecol. 2013; 2(2):199-203.
7.Das V, Jain S, Gupta H, Agarwal A, Pandey S, Amita. Evaluation of newer methods of early pregnancy termination. The Journal of Obs \& Gynec of India. 2005; 55(5): 454-56.

8.Goldberg AB, Dean G, Kang MS, Youssof S, Damey PD. Manual vs Electrical Vacuum Aspiration for early first trimester abortion: a controlled study of complication rates. Obstet gynecol. 2004; 103(1):101-7.

9.Nasira T, Mahmud G, Fatima S, Sultana M. Manual Vacuum Aspiration: A safe and cost effective substitute of Electrical Vacuum Aspiration for the surgical management of early pregnancy loss. JPMA. 2011; 61:149.

10.Westfall JM, O'brien-Gonzales A, Barley G. Journal of Women's health. 1998; 7(8): 559-62.

11.Edwards J, Crenin MD. Surgical abortion for gestation of less than 6 weeks: current problem. Obstet Gynecol and Fertil.1997; 20; 6-32.

Bijoy Kumar Dutta ${ }^{1}$, Sudip Samanta ${ }^{2}$

${ }^{1}$ Associate Professor, ${ }^{2}$ Post Graduate Trainee, Department of Obstetrics and Gynaecology, Gauhati Medical College, Guwahati, Assam, India 